\title{
Effects of postpartum oral calcium supplementation on milk yield, milk composition, and reproduction in multiparous Jersey and Jersey $\times$ Holstein crossbreed cows
}

\author{
Ainhoa Valldecabres ${ }^{1,2}$ (๑) and Noelia Silva-del-Río ${ }^{1,2 *}$ (]) \\ ${ }^{1}$ Veterinary Medicine Teaching and Research Center, 18830 Road 112, Tulare, CA 93274 \\ ${ }^{2}$ Department of Population Health and Reproduction, School of Veterinary Medicine, University of California, Davis 95616
}

\begin{abstract}
The objective of the present study was to evaluate the effects of postpartum oral calcium supplementation on milk yield, energy-corrected milk yield, milk fat concentration, milk protein concentration, and somatic cell count linear score across the first 3 monthly tests postpartum, peak milk yield, risk of pregnancy at first service, and hazard of pregnancy by $150 \mathrm{~d}$ in milk on 1,129 multiparous Jersey and Jersey $\times$ Holstein crossbreed cows from 2 commercial dairies. After calving, cows were systematically assigned to control (no oral calcium supplementation; $\mathrm{n}=567$ ) or oral calcium supplementation at 0 and $1 \mathrm{~d}$ in milk (oral Ca; 50 to $60 \mathrm{~g}$ of calcium as boluses; $\mathrm{n}=562$ ). Monthly test milk yield, composition, and somatic cell count information was obtained from the Dairy Herd Improvement Association. Herd records were used for reproductive data. Statistical analysis was conducted using generalized multiple linear, Poisson, and Cox's hazard regressions. Treatment effects were evaluated considering cow-level information available at parturition (parity, breed, previous lactation milk yield, previous lactation length, dry period length, gestation length, body condition, and locomotion score at calving, calving ease, and calf sex). In addition, for a subset of cows serum calcium concentration before treatment administration was evaluated $(\mathrm{n}=756)$. Overall, oral calcium supplementation did not affect the evaluated productive and reproductive variables. However, effects conditional to previous lactation length and calving locomotion score were observed. Milk yield and energy-corrected milk yield across the first 3 monthly tests were $1.8 \mathrm{~kg} / \mathrm{d}$ higher for supplemented cows with a previous lactation length within the fourth quartile, compared with control cows on the same quartile. Energy-corrected milk yield tended to
\end{abstract}

Received June 11, 2020.

Accepted August 20, 2020.

*Corresponding author: nsilvadelrio@ucdavis.edu be $1.1 \mathrm{~kg} / \mathrm{d}$ lower for supplemented cows with a previous lactation length within the first quartile, compared with control counterparts. Peak milk yield tended to be $1.6 \mathrm{~kg}$ higher for supplemented cows with a calving locomotion score $\geq 2$, compared with control cows with the same locomotion score. Treatment effects were not conditional to serum calcium concentration before treatment administration. Our results suggest that postpartum oral calcium supplementation effects are conditional to cow-level factors such as previous lactation length and calving locomotion score in multiparous Jersey and Jersey $\times$ Holstein crossbreed cows.

Key words: calcium, hypocalcemia, dairy cow, Jersey

\section{INTRODUCTION}

Transition cows face a sudden increase in nutrient requirements for milk production, which challenges their homeostatic mechanisms at a time when DMI and nutrient supply fall behind. When homeorhetic mechanisms fail to cope with these increased requirements, metabolic diseases may occur. Hypocalcemia is one of these metabolic diseases, a consequence of cows' inability to replace the extracellular calcium used to produce colostrum and milk (Goff, 2008). Clinical hypocalcemia is identified by US producers in $2.8 \%$ of cows (USDANAHMS, 2014a). However, subclinical hypocalcemia prevalence in multiparous cows is much higher $(\approx 50 \%$; Reinhardt et al., 2011). Subclinical hypocalcemia has been associated with increased risk of disease and impaired reproductive function (Ribeiro et al., 2013; Caixeta et al., 2017; Rodríguez et al., 2017). Controversially, the association of subclinical hypocalcemia with milk yield is unclear (Østergaard and Larsen, 2000; Chapinal et al., 2012; Jawor et al., 2012), likely because the degree of hypocalcemia, as well as the timing of the condition (day postpartum and duration) may play a role (McArt and Neves, 2020).

Peripartum calcium supplementation (injectable or oral) to prevent hypocalcemia is a management strategy implemented in $69 \%$ of US dairy herds (USDA- 
NAHMS, 2014b). Oral calcium supplementation has been proposed by some authors as the recommended approach for cows that are standing but may suffer from hypocalcemia (Oetzel, 2013), based on the premise that providing large amounts of highly soluble calcium forms creates a high concentration gradient between the digestive tract and extracellular fluids, leading to the passive absorption of ionized calcium (Goff, 2018). Additionally, some of the calcium forms used in the oral calcium formulation $\left(\mathrm{CaCl}_{2}\right)$ create an acidic response that might promote blood calcium increase by means such as increasing parathyroid hormone receptors expression and sensitivity (Goff et al., 2014; Rodríguez et al., 2016), or increase the ionized fraction of calcium (biologically active form; Pedersen, 1972). Oral calcium can be administered as liquid, paste, gel, or bolus; nevertheless, boluses are preferred due to their reduced risk of aspiration compared with the other forms (Oetzel, 2013). Postpartum oral calcium supplementation as boluses leads to a rapid but short increase in blood calcium concentration regardless of treatment length and calcium dose (Martinez et al., 2016a; Valldecabres et al., 2018).

Previous research conducted to assess long-term implications of postpartum oral calcium supplementation on Holstein cows observed minimal treatment effects at a group level, and suggests that productive and health responses to oral calcium supplementation are conditional to cow-level factors (parity, productive potential, gestation length, dry period length, and locomotion score), which also influence the direction of that response (Oetzel and Miller, 2012; Martinez et al., 2016b; Leno et al., 2018). Additionally, cow-level factors have also been associated with increased risk of hypocalcemia (Roche and Berry, 2006; Neves et al., 2017; Valldecabres et al., 2019). Therefore, the consideration of cow-level factors as part of hypocalcemia management programs involving oral calcium supplementation may be key to maximize its profitability; however, the diversity of currently identified cow-level factors complicates their adoption. Furthermore, although Jersey cows are at higher risk of hypocalcemia (Goff et al., 1995; Lean et al., 2006; Roche and Berry, 2006), to the best of our knowledge, long-term studies evaluating the implications of postpartum oral calcium supplementation have not been conducted with this breed or its crosses. In a previous study (Valldecabres et al., 2018), we observed an overall increase in serum calcium concentration, conditional to calcemic status before the administration of 50 to $60 \mathrm{~g}$ of calcium at 0 and 1 DIM as boluses in multiparous Jersey cows. Hence, we hypothesized that oral calcium supplementation with 50 to $60 \mathrm{~g}$ of calcium at 0 and 1 DIM as boluses would have implications on multiparous cows' productive and reproduc- tive outcomes. Thus, the objective of the present study was to evaluate the effects of postpartum oral calcium supplementation on milk yield and composition, risk of pregnancy at first service, and hazard of pregnancy by 150 DIM in multiparous Jersey and Jersey $\times$ Holstein crossbreed cows, considering cow-level information available at parturition, and for a subset of cows, also serum calcium concentration before supplementation.

\section{MATERIALS AND METHODS}

All procedures were approved by the University of California Davis Institutional Animal Care and Use Committee (\#18846).

\section{Study Herd Management}

The study was conducted on 2 commercial herds in California from November 2015 to May 2016 (herd 1) and from August to October 2016 (herd 2). Herd 1 milked 2,789 Jersey cows twice a day in a double herringbone parlor with an average 305-d mature equivalent milk yield of 8,748 kg. Herd 2 milked 9,660 Jersey and Jersey $\times$ Holstein crossbreed cows twice a day in a double herringbone parlor with an average 305-d mature equivalent milk yield of 9,697 kg.

On both herds, dry cows were moved to a close-up pen 3 wk before expected calving date and offered a TMR with anionic salts once a day; herd 1 TMR also included Zeolite (Table 1). Calves were separated from dams immediately after parturition in both herds. In herd 1, close-up cows showing secondary signs of calving were moved to a prepartum pen; once primary signs of calving were observed, cows were moved into individual calving pens bedded with straw. Twice a day, fresh cows were moved from the maternity pen to a colostrum pen where they stayed for $4 \mathrm{~d}$. From 4 to 14 DIM, cows were housed in a fresh cow pen. Cows housed in the colostrum and fresh cow pen were daily screened for health disorders by farm personnel. In herd 2, cows calved in the close-up pen and were moved twice a day to a fresh cow pen where they stayed up to 30 DIM and were screened daily for signs of disease by farm personnel. Farm personnel from both herds were allowed to use calcium sources to treat postpartum disorders following herd protocols. On both herds, oral calcium was part of supportive treatment for cows showing inappetence and additional postpartum disorders. Therapies requiring milk withdrawal were reported in both herds; additional information regarding health events and supportive treatments was recorded by farm personnel only in herd 1. Fresh cows in both herds were offered a TMR twice a day (Table 1 ). The voluntary waiting period was 49 d (end of the Presynch protocol) for both herds. Re- 
Table 1. Ingredients and nutrient composition of close-up and fresh cow rations

\begin{tabular}{|c|c|c|c|c|}
\hline \multirow[b]{2}{*}{ Item } & \multicolumn{2}{|c|}{ Close-up } & \multicolumn{2}{|c|}{ Fresh } \\
\hline & Herd 1 & Herd 2 & Herd 1 & Herd 2 \\
\hline \multicolumn{5}{|l|}{ Ingredient $(\%$ of $\mathrm{DM})$} \\
\hline Almond hulls & - & - & 5.10 & 5.00 \\
\hline Alfalfa hay & - & 23.76 & - & 15.00 \\
\hline Canola & 17.40 & 11.88 & 12.00 & 7.62 \\
\hline Close-up mineral & 3.10 & 8.51 & - & - \\
\hline Corn gluten & - & - & - & 16.19 \\
\hline Corn silage & 38.00 & 19.60 & 11.00 & 15.48 \\
\hline Cotton seed & - & - & - & 6.25 \\
\hline Distillers dried grains & - & - & 4.80 & 6.77 \\
\hline Lactating cow mineral & - & - & 0.10 & 5.44 \\
\hline Limestone & 3.10 & - & - & - \\
\hline Milo silage & - & 11.68 & - & - \\
\hline Mineral mix & - & - & 4.20 & - \\
\hline Rolled corn & 13.60 & 23.37 & 15.00 & 16.33 \\
\hline Rumen-protected AA & - & - & 2.30 & - \\
\hline Rumen-protected fat & - & 1.19 & 0.20 & 1.45 \\
\hline Sorghum & - & - & 2.40 & - \\
\hline Soy hulls & 14.90 & - & 3.40 & - \\
\hline Straw & 9.30 & - & - & - \\
\hline Yeast & - & - & - & 0.06 \\
\hline Whey & - & - & - & 4.43 \\
\hline Winter forage & - & - & 40.00 & - \\
\hline Zeolite & 0.60 & - & - & - \\
\hline \multicolumn{5}{|c|}{ Nutrient composition ${ }^{1}$ (DM basis) } \\
\hline $\mathrm{CP}(\%)$ & 16.25 & 14.10 & 17.25 & 17.30 \\
\hline $\mathrm{CF}(\%)$ & 2.48 & 2.88 & 3.98 & 4.72 \\
\hline $\mathrm{ADF}(\%)$ & 26.30 & 22.10 & 20.10 & 17.60 \\
\hline $\mathrm{NDF}(\%)$ & 37.75 & 31.50 & 30.45 & 26.90 \\
\hline Lignin $(\%)$ & 4.17 & 4.78 & 4.66 & 4.95 \\
\hline Starch $(\%)$ & 18.85 & 25.30 & 22.05 & 22.40 \\
\hline Ash (\%) & 14.87 & 12.79 & 8.88 & 9.51 \\
\hline $\mathrm{Ca}(\%)$ & 2.86 & 2.46 & 1.19 & 1.45 \\
\hline $\mathrm{P}(\%)$ & 0.40 & 0.41 & 0.48 & 0.58 \\
\hline $\operatorname{Mg}(\%)$ & 0.43 & 0.59 & 0.36 & 0.44 \\
\hline $\mathrm{K}(\%)$ & 1.27 & 1.33 & 1.37 & 1.76 \\
\hline $\mathrm{S}(\%)$ & 0.47 & 0.33 & 0.34 & 0.39 \\
\hline $\mathrm{Na}(\%)$ & 0.13 & 0.25 & 0.29 & 0.50 \\
\hline $\mathrm{Cl}(\%)$ & 0.92 & 1.46 & 0.43 & 0.48 \\
\hline $\operatorname{DCAD}^{2}(\mathrm{mEq} / 100 \mathrm{~g})$ & -17.61 & -16.80 & 14.55 & 29.40 \\
\hline
\end{tabular}

${ }^{1}$ Wet chemistry analysis (Cumberland Valley Analytical Services; Hagerstown, MD).

${ }^{2}$ DCAD calculations were performed according to the following equation: DCAD $(\mathrm{mEq} / 100 \mathrm{~g})=[(\mathrm{Na}+\mathrm{K})$ $-(\mathrm{Cl}+\mathrm{S})]$.

productive management at first service in both herds involved Presynch from 35 DIM with 2 doses of $\mathrm{PGF}_{2 \alpha}$ given $14 \mathrm{~d}$ apart. Tailheads of cows were painted with chalk daily for heat detection. Cows showing estrus following the Presynch protocol were inseminated, and cows not showing estrus entered the Ovsynch protocol. On average $82 \%$ of the cows were inseminated after heat detection (oral $\mathrm{Ca}: 81.8 \%$; control: $82.1 \%$ ) and $18 \%$ following the Ovsynch protocol (oral Ca: $18.2 \%$; control: $17.9 \%$ ). Pregnancy diagnosis was performed by transrectal palpation 36 to $42 \mathrm{~d}$ postbreeding. On herd 1 , management of cows after nonpregnancy diagnosis at second and later service varied based on the ovarian structures identified by transrectal examination at pregnancy diagnosis. Cows with a corpus luteum were administered a dose of $\mathrm{PGF}_{2 \alpha}$ and monitored for estrus signs; if estrus not observed in $2 \mathrm{wk}$, cows were enrolled in the Ovsynch protocol, and cows with a follicle or no apparent structures at pregnancy diagnosis were given GnRH and enrolled in the Ovsynch protocol. On herd 2 , open cows were resynchronized with a dose of $\mathrm{PGF}_{2 \alpha}$ at the time of negative pregnancy diagnosis, followed by $\mathrm{GnRH}$ and timed insemination. Both herds used sexed semen in their reproductive protocols.

\section{Experimental Design}

A total sample size of 952 cows was calculated to allow for the detection of a 2-kg milk difference among treatments with an $\alpha$ level of 0.05 and power of 0.90 using the POWER procedure of SAS (version 9.4, SAS Institute Inc., Cary, NC). The variation in milk 
yield $(\mathrm{SD}=9.5 \mathrm{~kg})$ was determined with the 2014 first monthly test records, obtained from the DHIA for the 2 study herds. A total of 1,175 multiparous cows were alternatively assigned at calving time to 1 of the 2 treatment groups based on calving time: control (no oral calcium supplementation; herd $1: \mathrm{n}=344$; herd 2 : $\mathrm{n}=237$ ) or oral calcium supplementation [oral Ca; 2 doses of QuadriCalMINI (Bio-Vet Inc., Barneveld, WI) each containing 50 to $60 \mathrm{~g}$ of $\mathrm{Ca}$; herd $1: \mathrm{n}=364$; herd $2: \mathrm{n}=230]$; researchers assigned the first enrolled cow to the control group.

Each oral calcium dose included 5 boluses as per label indication. Boluses were composed by $\mathrm{CaCl}_{2}$ as the main calcium source, and calcium propionate, calcium lactate, and $\mathrm{CaSO}_{4}$ as secondary sources. Boluses also contained an undisclosed amount of niacin and vitamin $\mathrm{D}_{3}$. Researchers administered the first oral calcium dose in the maternity pen at $2 \mathrm{~h} 55 \mathrm{~min} \pm 2 \mathrm{~h} 10$ min (mean $\pm \mathrm{SD}$ ) and at $3 \mathrm{~h} 26 \mathrm{~min} \pm 2 \mathrm{~h} 24$ min (mean $\pm \mathrm{SD}$ ) after calving (0 DIM) on herd 1 and 2, respectively. The second oral calcium dose was administered by the researchers at lock-up time during the fresh cow check, at $29 \mathrm{~h} 36 \mathrm{~min} \pm 5 \mathrm{~h} 54$ min (mean $\pm \mathrm{SD}$ ) and at $26 \mathrm{~h}$ 9 min \pm 2 h 12 min (mean \pm SD) after calving (1 DIM) on herd 1 and 2, respectively. Farm employees were blind to treatment assignment.

\section{Sample Collection and Laboratory Analyses}

A total of 756 cows [oral Ca: herd $1(\mathrm{n}=148)$ and herd $2(\mathrm{n}=241)$; control: herd $1(\mathrm{n}=143)$ and herd 2 $(\mathrm{n}=224)]$ had a blood sample collected from the coccygeal vessels before first treatment administration. An evacuated tube without anticoagulant (BD Vacutainer, Trace Element Serum; BD, Franklin Lakes, NJ) was used for sample collection. Samples were collected at 2 $\mathrm{h} 31 \mathrm{~min} \pm 1 \mathrm{~h} 51 \mathrm{~min}$ (mean $\pm \mathrm{SD}$ ) and at $3 \mathrm{~h} 18 \mathrm{~min}$ $\pm 2 \mathrm{~h} 17$ min (mean $\pm \mathrm{SD}$ ) after calving in herd 1 and 2 , respectively. Immediately after drawing blood, samples were placed into a portable refrigerator set at $4{ }^{\circ} \mathrm{C}$ and transported to the laboratory within $3 \mathrm{~h}$ after collection. Samples were centrifuged at $1,430 \times g$ for $15 \mathrm{~min}$ at $15^{\circ} \mathrm{C}$ and serum was stored at $-20^{\circ} \mathrm{C}$ until analysis. Frozen serum samples were shipped to the California Animal Health Food Safety Laboratory (University of California, Davis) for calcium analyses by inductively coupled plasma-optical emission spectrometry (Melton et al., 1990). The intra- and interassay coefficients of variation were 2.0 and $4.4 \%$, respectively.

Samples of the close-up and fresh TMR were collected at the beginning and end of the study period for herd 1 and at the end of the study period for herd 2. Samples were collected from 5 different feed bunk locations at feeding time, composited, dried, ground, and analyzed by wet chemistry (Cumberland Valley Analytical Services, Hagerstown, MD; Table 1).

\section{Data Collection}

A single researcher scored cows at calving for body condition using a 1 to 5 scale with 0.25 increments (Ferguson et al., 1994), and for locomotion using a 5-point scale (Sprecher et al., 1997). Cow-level factors considered as covariates were obtained from DairyComp305 records (Valley Ag Software, Tulare, CA), DHIA (AgriTech Analytics, Visalia, CA), and on-farm records and included previous lactation 305-d mature equivalent milk yield and length, gestation length, dry and closeup periods length, parity, calving ease, calf sex, stillbirths, and twin births. Data for the evaluated productive outcomes (milk yield, milk fat concentration, milk protein concentration, and SCC) were obtained from DHIA records. Breeding information and data for the evaluated reproductive outcomes were obtained from the DairyComp305 and DHIA records. First monthly test occurred from 5 to 36 DIM, second from 33 to 70 DIM, and third from 61 to 99 DIM.

\section{Statistical Analyses}

Study outcomes included milk yield, ECM yield $[($ milk yield $\times 0.327)+($ milk fat yield $\times 12.86)+$ (milk protein yield $\times$ 7.65); Siverson et al., 2014], fat concentration, protein concentration, and SCC linear score $\left[\log _{2}(\mathrm{SCC} / 100)+3\right]$ across the first 3 monthly tests, peak milk yield (highest milk yield record among the first 3 monthly tests), risk of pregnancy at first service, and hazard of pregnancy by 150 DIM. The present study was not designed to assess treatment effects on disease incidence, and thus disease was not evaluated as a study outcome.

Treatment effects were evaluated considering cowlevel information available at parturition and for a subset of cows, the effect of serum calcium concentration before oral calcium supplementation was also evaluated. Based on previous research (Oetzel and Miller, 2012; Martinez et al., 2016b), previous lactation 305-d mature equivalent milk yield was offered as a dichotomized variable; a relative to herd milk production rank (Rank305ME) was calculated for each cow dividing its previous lactation 305-d mature equivalent milk yield, by the respective herd average, and multiplying by 100 . Then, cows were classified as being $>$ or $\leq 105$ Rank305ME. To facilitate interpretation, limit model assumptions on dependent and independent variables relationship, and minimize collinearity, additional continuous variables (previous lactation length, dry period length, and gestation length) were categorized 
into quartiles before statistical analysis as first quartile $(\leq 25$ th percentile), second quartile $(>25$ th to $\leq 50$ th percentile), third quartile ( $>50$ th to $<75$ th percentile), and fourth quartile ( $\geq 75$ th percentile). The first to fourth quartile means $( \pm \mathrm{SD})$ were as follows for previous lactation length $(271 \pm 18,294 \pm 7,320 \pm 10$, and $398 \pm 54 \mathrm{~d})$, dry period length $(43 \pm 4,51 \pm 2,61 \pm$ 5, and $103 \pm 27 \mathrm{~d}$ ), and gestation length (274 $\pm 4,279$ $\pm 1,281 \pm 1$, and $287 \pm 3 \mathrm{~d}$ ). Variables considered for inclusion in all models were herd, parity (second, third, and $\geq$ fourth), Rank305ME, previous lactation length, dry period length, and gestation length in quartiles, $\operatorname{BCS}(\leq 2.50,2.75$ to 3.25 , and $\geq 3.50$ ), and locomotion score at calving ( 1 and $\geq 2$ ), calving ease (assisted and not assisted calving), and calf sex (sex of twin births was considered male if at least one of the calves was male). Additionally, DIM at peak and DIM at first service and breeding code (timed AI and heat breeding) were considered for inclusion in the peak milk yield and pregnancy risk at first service models, respectively. All independent variables were treated as fixed effects in the statistical models. Due to the nonconcurrent enrollment of the 2 study herds, information regarding to date of the event and season were not considered as independent explanatory variables. Effect of twin births was not considered due to the low prevalence observed in the study herds (4.6 and $3.6 \%$ for oral Ca and control cows, respectively; $P=0.41)$. Similarly, the effect of stillbirths was not considered due to inconsistent herd records. Disease incidence was not considered as an independent variable in the statistical models, and cows receiving additional calcium administered by farm personnel remained in the analyses. Treatment by breed effect was evaluated on Jersey and Jersey $x$ Holstein crossbreed cows from herd 2; models, as described in the following paragraphs, were built for each one of the study outcomes (results not reported). No significant treatment by breed effect was observed for any of the study outcomes (lowest $P$-value observed for the interaction $=0.48)$. Thus, breed was dismissed as an independent explanatory variable.

All statistical analyses were performed in SAS version 9.4. The SGPLOT procedure was used to generate raw data plots before statistical analyses. Based on the generated plots, productive data analysis was limited to the first 3 monthly tests. Descriptive statistics were performed using the MEANS, TTEST, and FREQ procedures. Variance inflation factor of the REG procedure was used to evaluate the collinearity between all potential explanatory variables for each study outcome. Collinearity (variance inflation factor $>10$; Dohoo et al., 2012) was not detected and all potential explanatory variables were considered for all study outcomes.
Productive outcomes across the first 3 monthly tests were analyzed by generalized multiple linear regression using the MIXED procedure. The Kenward-Roger method was used to estimate the denominator degrees of freedom. Cow was the subject effect of the repeated statement allowing for random intercept, with the variance-covariance structure leading to the lowest Akaike's information criterion selected at the beginning of the model building processes, and reevaluated in the final models. Unstructured, compound symmetry, autoregressive 1 , heterogeneous autoregressive 1, Toeplitz, and Toeplitz heterogeneous were the variancecovariance structures evaluated. Homoscedasticity and independence of errors assumption was assessed with final models' residual plots. Observations with studentized residuals $>|4|$ were individually evaluated to check for possible outliers. No observations were excluded from the analyses for that reason.

Risks of pregnancy at first service was analyzed by Poisson regression with the GENMOD procedure (Ospina et al., 2012). Adequacy of the Poisson distribution was assessed using the MEANS procedure. The $\log$ link function and the LSMEANS statement with the exp option were used to obtain treatment risk ratio (RR) and its Wald 95\% confidence interval. The RR represents the ratio of the probability of pregnancy success from first breeding for cows supplemented with oral calcium to the probability for control cows. Overall model fit was assessed with the goodness-of-fit chi-squared test.

Hazard of pregnancy by 150 DIM was analyzed with Cox proportional hazards regression using the PHREG procedure. Right censoring was applied for cows present in the herd without a conception date, or dead or sold by 150 DIM. Final model estimates were compared with those from models assuming complete positive and negative correlation to assess the independence of censoring assumption (Dohoo et al., 2012). In our study, censoring was considered as noninformative; model estimates changed $27 \%$, whereas the effects remained unchanged. The proportional hazards assumption was graphically assessed by plotting the logarithm of the hazard function by the logarithm of the time using the LIFETEST procedure. The proportional hazards assumption was considered met when the curves for the groups within a categorical predictor were parallel (Dohoo et al., 2012). Deviance residuals plots were generated to assess overall model fit.

For all outcomes, base models were created via manual backward stepwise elimination of explanatory variables with $P>0.10$. Treatment and herd effects were forced into all models regardless of the $P$-value. Subsequently, interactions among treatment and ad- 
ditional explanatory variables were individually offered to the base model, regardless of the significance of the main effect. All interactions resulting in $P<0.05$ were simultaneously offered to the base model. Final models were then created as described for the base models; interactions of explanatory variables with treatment and single explanatory variables were removed at $P>0.05$, with the last ones only removed when no interaction included them. If variables categorized in 4 quartiles remained in the final model, and no differences were observed among the second and third quartile, those 2 categories were collapsed (interquartile range) to facilitate interpretation. For the subset of cows with serum calcium concentration determined before treatment administration, base models for each study outcome were developed as described previously with the addition of serum calcium concentration, and the treatment by serum calcium concentration interaction subsequently evaluated as earlier described. To limit pairwise comparisons to those of interest (among treatments, and treatments at each level of the independent variables forming the interactions in the final models), customized hypothesis tests were generated using the PLM procedure with the slice option and Tukey adjustment for the generalized multiple linear regression models. Significance was declared at $P \leq 0.05$ and trends at $0.05<P \leq 0.10$.

\section{RESULTS}

A total of 46 cows [oral Ca $(\mathrm{n}=32)$; control $(\mathrm{n}=$ 14)] were excluded from the analysis due to incomplete study protocol compliance [missed $(\mathrm{n}=23)$ or received an additional $(\mathrm{n}=1)$ calcium dose administered by research personnel], or inconsistent data collection (n $=22$ ). The final number of cows included in the study was 1,129 [oral Ca: herd $1(\mathrm{n}=349)$ and herd $2(\mathrm{n}=$ 213); control: herd $1(\mathrm{n}=330)$ and herd $2(\mathrm{n}=237)]$. The characteristics of cows included in the analyses are summarized in Table 2. Overall, the prevalence of subclinical hypocalcemia [serum calcium $\leq 2.12 \mathrm{mmol} / \mathrm{L}$ $(\leq 8.5 \mathrm{mg} / \mathrm{dL})]$ before treatment initiation was $50 \%$ [oral Ca (50.2\%); control (49.8\%)]. Early lactation disease and additional calcium therapy herd records were only available for herd 1; retained placenta, metritis, milk fever, and additional Ca therapy administered by farm personnel were recorded respectively for 1.8, 2.5, 0.6 , and $1.5 \%$ of oral $\mathrm{Ca}$, and $1.8,2.9,0.6$, and $2.5 \%$ of control cows. Mastitis was recorded for 3.8 and $4.3 \%$ of oral $\mathrm{Ca}$ and control cows from both herds, respectively. Both herds fed negative DCAD prepartum diets as a prophylactic strategy for hypocalcemia. In addition, herd 1 included in the prepartum diet Zeolite, a mycotoxin binder with $\mathrm{Ca}$ binding properties at a very low inclusion rate $(0.6 \%$ of DM; Table 1$)$.

Table 2. Descriptive statistics for categorical (proportions) and continuous (mean $\pm \mathrm{SD}$ ) cow-level variables from oral $\mathrm{Ca}(\mathrm{n}=559)$ and control $(\mathrm{n}=570)$ cows included in the analyses

\begin{tabular}{|c|c|c|c|}
\hline \multirow[b]{2}{*}{ Item } & \multicolumn{2}{|c|}{ Treatment $^{1}$} & \multirow[b]{2}{*}{$P$-value } \\
\hline & Oral Ca & Control & \\
\hline \multicolumn{3}{|l|}{ Parity (\%) } & \multirow[t]{4}{*}{0.89} \\
\hline Second & 37.8 & 36.7 & \\
\hline Third & 27.3 & 28.3 & \\
\hline$\geq$ Fourth & 34.9 & 35.0 & \\
\hline \multicolumn{3}{|l|}{ BCS at calving $(\%)$} & \multirow{4}{*}{0.09} \\
\hline$\leq 2.5$ & 10.5 & 7.4 & \\
\hline$\overline{2} .75-3.25$ & 79.8 & 84.7 & \\
\hline$\geq 3.5$ & 9.7 & 7.9 & \\
\hline $\operatorname{Lame}^{2}(\%)$ & 8.8 & 8.5 & 0.81 \\
\hline Assisted calving (\%) & 8.0 & 9.8 & 0.29 \\
\hline Male calving ${ }^{3}(\%)$ & 21.2 & 20.1 & 0.67 \\
\hline Twin calving (\%) & 4.4 & 3.6 & 0.41 \\
\hline 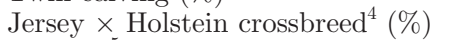 & 19.1 & 19.2 & 0.95 \\
\hline $\operatorname{Calcium}^{5}(\mathrm{mmol} / \mathrm{L})$ & $2.02 \pm 0.25$ & $2.04 \pm 0.21$ & 0.27 \\
\hline Days dry (d) & $60 \pm 26$ & $62 \pm 28$ & 0.14 \\
\hline Gestation length (d) & $280 \pm 6$ & $280 \pm 6$ & 0.55 \\
\hline Previous lactation 305-d $\mathrm{MEQ}^{6}(\mathrm{~kg})$ & $9,077 \pm 1,370$ & $8,957 \pm 1,383$ & 0.15 \\
\hline Previous lactation length $(\mathrm{d})$ & $316 \pm 52$ & $317 \pm 60$ & 0.80 \\
\hline \multicolumn{4}{|c|}{${ }^{1}$ Oral Ca: cows received 50 to $60 \mathrm{~g}$ of $\mathrm{Ca}$ at 0 and 1 DIM. Control: no Ca administration. } \\
\hline \multicolumn{4}{|c|}{${ }^{2}$ Cows with not normal gait, scored $\geq 2$ at calving (Sprecher et al., 1997). } \\
\hline \\
\hline \multicolumn{4}{|c|}{${ }^{4}$ Jersey $\times$ Holstein crossbreed cows were all enrolled from the same herd. } \\
\hline \multicolumn{4}{|c|}{$\begin{array}{l}{ }^{5} \text { Serum Ca concentration was assessed within } 5 \mathrm{~h} \text { postpartum for oral } \mathrm{Ca}(\mathrm{n}=389) \text { and control cows }(\mathrm{n}=367) \\
{ }^{6} \mathrm{MEQ}=\text { mature equivalent milk yield. }\end{array}$} \\
\hline
\end{tabular}




\section{Milk Yield and Composition}

Milk Yield. Overall, milk yield across the first 3 monthly tests was not different for oral $\mathrm{Ca}(31.6 \mathrm{~kg} / \mathrm{d})$ and control cows $(31.5 \mathrm{~kg} / \mathrm{d} ; P=0.65)$. Nevertheless, a treatment by previous lactation length effect was observed ( $P=0.007$; Table 3$)$. Milk yield was 1.8 $\mathrm{kg} / \mathrm{d}$ higher for oral Ca cows with a previous lactation length within the fourth quartile $[\geq 339 \mathrm{~d} ; 390 \pm$ $55 \mathrm{~d}$ (mean $\pm \mathrm{SD})$ ], compared with control cows with previous lactation length within the same quartile $(P$ $=0.008)$. Additional effects included in the model were herd $(P=0.19)$, test number $(P<0.001)$, parity $(P$ $<0.001)$, Rank305ME $(P<0.001)$, dry period length $(P<0.001)$, and calving BCS $(P=0.01)$. Treatment effects on milk yield across the first 3 monthly tests were not conditional to serum calcium concentration before oral calcium supplementation $(P=0.34)$, while including in the model the effects of serum calcium $(P$ $=0.002)$, treatment $(P=0.36)$, herd $(P<0.001)$, test number $(P<0.001)$, parity $(P<0.001)$, Rank305ME $(P<0.001)$, and dry period length $(P=0.002)$.

Peak Milk Yield. Overall, peak milk yield was not different for oral $\mathrm{Ca}(35.9 \mathrm{~kg})$ and control cows (35.3 $\mathrm{kg} ; \quad P=0.21)$. Nevertheless, a treatment by calving locomotion score effect was observed $(P=0.05$; Table $3)$. Peak milk yield tended to be $1.6 \mathrm{~kg}$ higher for oral
Ca cows with calving locomotion score $\geq 2$, compared with control cows with the same calving locomotion score $(P=0.08)$. Additional effects included in the model were herd $(P=0.04)$, parity $(P<0.001)$, previous lactation length $(P=0.002)$, Rank305ME $(P<$ $0.001)$, dry period length $(P<0.001)$, and calving BCS $(P=0.02)$. Treatment effects on peak milk yield were not conditional to serum calcium concentration before oral calcium supplementation $(P=0.28)$, while including in the model the effects of serum calcium $(P=$ $0.002)$, treatment $(P=0.28)$, herd $(P<0.001)$, DIM at peak $(P=0.02)$, parity $(P<0.001)$, Rank305ME $(P$ $<0.001)$, and dry period length $(P=0.004)$.

ECM Yield. Overall, ECM yield across the first 3 monthly tests was not different for oral Ca $(37.1 \mathrm{~kg} / \mathrm{d})$ and control cows $(37.1 \mathrm{~kg} / \mathrm{d} ; P=0.93)$. However, a treatment by previous lactation length effect was observed $(P=0.005$; Table 3$)$. Milk yield was $1.8 \mathrm{~kg} / \mathrm{d}$ higher for oral Ca cows with a previous lactation length within the fourth quartile [ $\geq 339 \mathrm{~d} ; 390 \pm 55 \mathrm{~d}$ (mean $\pm \mathrm{SD}$ ); $P=0.01$ ], and tended to be $1.3 \mathrm{~kg} / \mathrm{d}$ lower for oral Ca cows with a previous lactation length within the first quartile $[\leq 287 \mathrm{~d} ; 274 \pm 17 \mathrm{~d}$ (mean $\pm \mathrm{SD}) ; P$ $=0.07$ ), compared with control cows with previous lactation length within the same quartiles. Other effects accounted for in the model were herd $(P<0.001)$, test number $(P<0.001)$, parity $(P<0.001)$, Rank305ME

Table 3. Least squares means and SEM for oral Ca and control cows' milk yield and composition across the first 3 monthly tests postpartum and peak milk yield

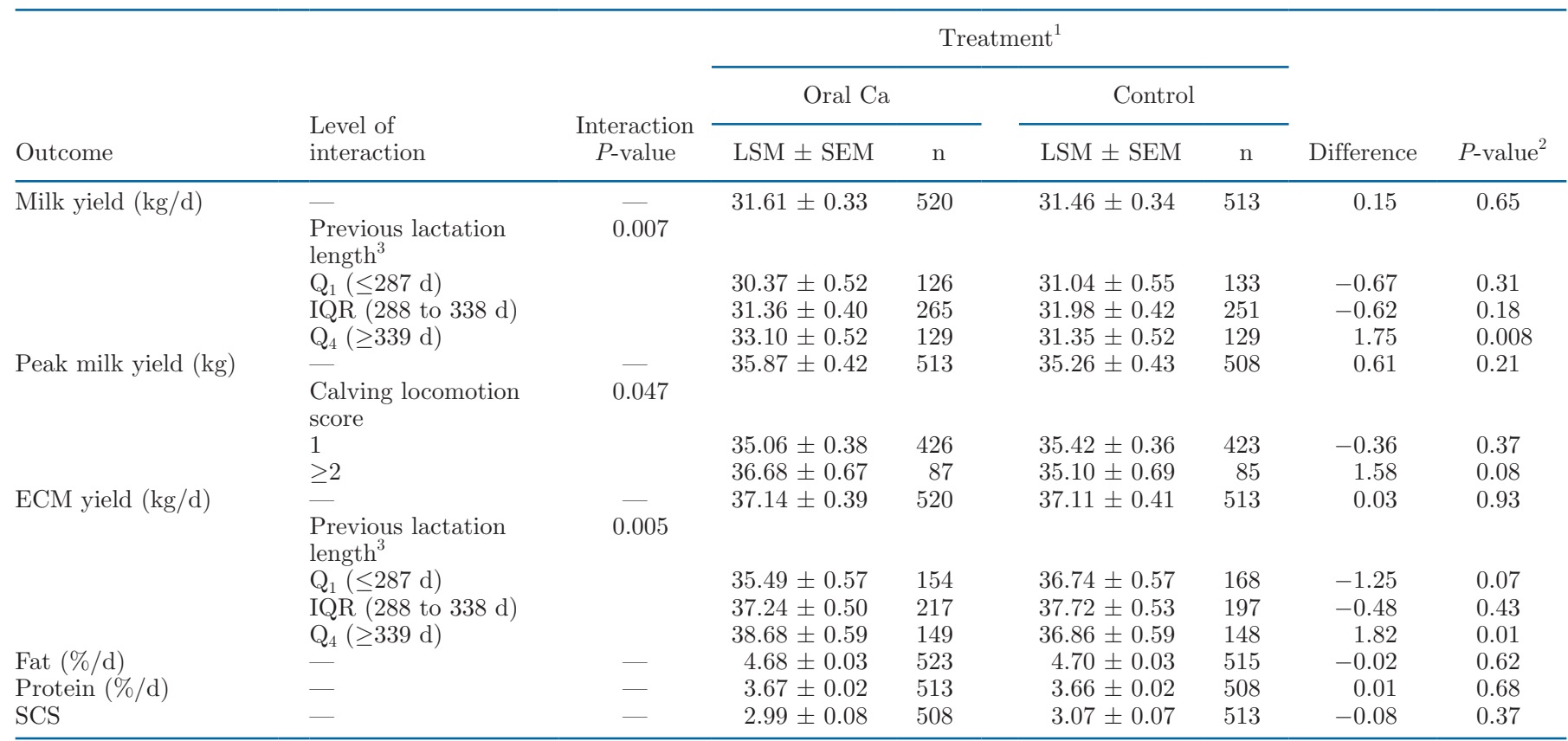

${ }^{1}$ Oral Ca: cows received 50 to $60 \mathrm{~g}$ of oral Ca at 0 and 1 DIM. Control: no oral Ca administration.

${ }^{2}$ Contrast $P$-values adjusted for multiple comparisons by Tukey.

${ }^{3}$ Previous lactation length categorized as first quartile $\left(\mathrm{Q}_{1}\right)$, interquartile range (IQR), and fourth quartile $\left(\mathrm{Q}_{4}\right)$. 
$(P<0.001)$, dry period length $(P<0.001)$, and calving BCS $(P=0.004)$. Treatment effects on ECM yield across the first 3 monthly tests were not conditional to serum calcium concentration before oral calcium supplementation $(P=0.41)$, while including in the model the effects of serum calcium $(P=0.005)$, treatment $(P=0.45)$, herd $(P<0.001)$, test number $(P<$ $0.001)$, parity $(P=0.04)$, Rank305ME $(P<0.001)$, and calving BCS $(P=0.03)$.

Fat Concentration. Milk fat concentration across the first 3 monthly tests was not different for oral $\mathrm{Ca}(4.64 \% / \mathrm{d})$ and control cows $(4.66 \% / \mathrm{d} ; P=0.60$; Table 3), while accounting for the effects of herd $(P<$ $0.001)$, test number $(P<0.001)$, parity $(P<0.001)$, Rank305ME $(P<0.001)$, and calving BCS $(P=0.02)$. No significant interactions involving treatment were observed. Effects of oral calcium supplementation on milk fat concentration across the first 3 monthly tests were not conditional to serum calcium concentration before supplementation $(P=0.95)$, while including in the model the effects of serum calcium $(P=0.44)$, treatment $(P=0.85)$, herd $(P<0.001)$, test number $(P<0.001)$, parity $(P=0.04)$, and Rank305ME $(P<$ $0.001)$.

Protein Concentration. Milk protein concentration across the first 3 monthly tests was not different for oral $\mathrm{Ca}(3.67 \% / \mathrm{d})$ and control cows $(3.66 \% / \mathrm{d} ; P$ $=0.68$; Table 3), while accounting for the effects of herd $(P=0.28)$, test number $(P<0.001)$, parity $(P<$ 0.001), Rank305ME $(P<0.001)$, dry period length $(P$ $<0.001)$, and calving ease $(P=0.02)$. No significant interactions involving treatment were observed. Effects of oral calcium supplementation on milk protein concentration across the first 3 monthly tests were not conditional to serum calcium concentration before supplementation $(P=0.72)$, while including in the model the effects of serum calcium $(P<0.001)$, treatment $(P=0.75)$, herd $(P=0.12)$, test number $(P<0.001)$, parity $(P<0.001)$, Rank305ME $(P<0.001)$, and dry period length $(P<0.001)$.

$S C C$ Linear Score. Overall, SCC linear score across the first 3 monthly tests was not affected by treatment (2.99 and 3.07 for oral $\mathrm{Ca}$ and control cows, respectively; $P=0.37$; Table 3 ). No significant interactions involving treatment were observed while accounting for the effects of herd $(P<0.001)$, test number $(P=$ $0.008)$, and parity $(P<0.001)$. Effects of oral calcium supplementation on SCC linear score across the first 3 monthly tests were not conditional to serum calcium concentration before supplementation $(P=0.71)$, while including in the model the effects of serum calcium $(P$ $=0.69)$, treatment $(P=0.79)$, herd $(P<0.001)$, test number $(P=0.02)$, and parity $(P<0.001)$.

\section{Reproduction}

Pregnancy at First Service. Overall pregnancy to first service was $31.3 \%$ (oral Ca: $30.7 \%$; control: $31.9 \%$ ). Risk of pregnancy at first service was not affected by treatment $(\mathrm{RR}=0.90 ; 95 \% \mathrm{CI}: 0.72$ to $1.13 ; P=0.38)$, while accounting for the effects of herd $(P=0.67)$, parity $(P=0.03)$, previous lactation length $(P=0.006)$, calf sex $(P=0.02)$, and breeding code $(P=0.006)$. No significant interactions involving treatment were observed. Effects of oral calcium supplementation on risk of pregnancy to first service were not conditional to serum calcium concentration before supplementation $(P=0.97)$, while including in the model the effects of serum calcium $(P=0.08)$, treatment $(P=0.95)$, herd $(P=0.25)$, previous lactation length $(P=0.05)$, calf sex $(P=0.03)$, and breeding code $(P=0.002)$.

Pregnancy by 150 DIM. The proportion of cows pregnant by 150 DIM was 67.3 and $66.6 \%$ for oral Ca and control cows, respectively. Hazard of pregnancy by 150 DIM was not affected by treatment (hazard ratio $=1.04 ; 95 \%$ CI: 0.90 to $1.20 ; P=0.64)$, while including the effects of herd $(P=0.16)$, parity $(P<$ $0.001)$, previous lactation length $(P<0.001)$, calving locomotion score $(P=0.002)$, and calf sex $(P=0.008)$. No significant interactions involving treatment were observed. Effects of oral calcium supplementation on hazard of pregnancy by 150 DIM were not conditional to serum calcium concentration before supplementation $(P=0.73)$, while including in the model the effects of serum calcium $(P=0.13)$, treatment $(P=0.69)$, herd $(P=0.008)$, and parity $(P=0.05)$.

\section{DISCUSSION}

The objective of the present study was to evaluate the effects of postpartum oral calcium supplementation on milk yield and composition, risk of pregnancy at first service, and hazard of pregnancy by 150 DIM in multiparous Jersey and Jersey $\times$ Holstein crossbreed cows, considering cow-level information available at parturition, and for a subset of cows, also serum calcium concentration before supplementation. Prior studies have evaluated postpartum oral calcium supplementation as a management strategy for hypocalcemia in Holstein cows, but limited information is available for Jersey cows. In a prior study, multiparous Jersey cows supplemented with 50 to $60 \mathrm{~g}$ of calcium at 0 and 1 DIM showed an overall increase in serum calcium concentration (Valldecabres et al., 2018). This improvement in calcemia was expected to influence multiparous cows' productive and reproductive outcomes. Overall, oral calcium supplementation had minimal effects at 
the group level in the presented study. Observed effects on milk and ECM yield across the first 3 monthly tests and peak milk yield were conditional to previous lactation length and calving locomotion score, respectively. No effects of oral calcium supplementation were observed on reproductive outcomes.

Subclinical hypocalcemia is considered a gateway condition for peripartum diseases, which in turn are negatively associated with productive and reproductive outcomes (Ribeiro et al., 2013; Martinez et al., 2016b; Rodríguez et al., 2017). A limitation of the present study is that treatment effects on disease incidence were not evaluated since health records were not available for herd 2, and as previously described, disease incidence was too low on herd 1 to achieve enough power for its evaluation as an study outcome. However, the results presented here are not affected by the lack of disease information. Although peripartum disease may influence the evaluated outcomes, previous research has shown that diseases such as retained placenta, metritis, displaced abomasum, and mastitis are affected by oral calcium supplementation (Leno et al., 2018), and therefore, even if the information was available, it should not be considered as a covariate in the statistical models.

Oral calcium supplementation did not have an overall effect on Jersey and Jersey $\times$ Holstein crossbreed cows' milk yield across the first 3 monthly tests or at peak, as previously reported in Holstein cows (Oetzel and Miller, 2012; Martinez et al., 2016b; Leno et al., 2018). But supplemented cows with a previous lactation length within the fourth quartile and compromised gait at calving (calving locomotion score $\geq 2$ ), had and tended to have greater milk yield across the first 3 monthly tests and at peak, respectively. Oral calcium supplementation by locomotion score effects have been previously reported for health outcomes. Within the first 30 DIM, supplemented lame cows had a lower sum of health events in the study by Oetzel and Miller (2012), and lower risk of displaced abomasum in the study by Leno et al. (2018). A lower incidence of health disorders could translate on higher milk yield; however, in the aforementioned studies, effects of oral calcium supplementation on milk yield were conditional to multiparous cows' productive potential and gestation length.

To the best of our knowledge, the present study is the first one to evaluate the effects of oral calcium supplementation on ECM yield and milk composition. Energy-corrected milk yield effects were conditional to previous lactation length. Across the first 3 monthly tests, ECM yield was higher for supplemented cows with a previous lactation length within the fourth quartile but tended to be lower for supplemented cows with a previous lactation length within the first quartile. Longer previous lactation has been identified as a risk factor for subclinical hypocalcemia in Jersey cows (Valldecabres et al., 2019) and associated with increased odds of disease during the first 30 DIM in Holstein cows (Vergara et al., 2014); however, previous studies on oral calcium supplementation did not identify previous lactation length as a conditional factor for treatment effect on Holstein cows (Oetzel and Miller, 2012) or did not evaluate it (Martinez et al., 2016b; Leno et al., 2018). Lactation length is potentially associated with milk production; positive and negative milk yield responses after oral calcium supplementation have been reported for high- and low-producing Holstein cows, respectively (Oetzel and Miller, 2012; Martinez et al., 2016b). Breed differences may be behind the differences on the observed results; however, the present study cannot provide a biological explanation of our findings. Milk fat and protein concentration across the first 3 monthly tests were not affected by oral calcium supplementation in our study. Similarly, a study administering calcium subcutaneously postpartum observed no effect on milk fat and protein concentration across the first 3 monthly tests (Amanlou et al., 2016).

Treatment effects on SCC linear score across the first 3 monthly tests were not detected. Effects of calcium supplementation on SCC have not been commonly evaluated; nevertheless, supplementing calcium subcutaneously decreased SCC across the first 3 monthly tests (Amanlou et al., 2016). Effects of oral calcium supplementation on mastitis risk within the first 30 DIM were not observed in Holstein cows (Oetzel and Miller, 2012; Leno et al., 2018). The low mastitis incidence (abnormal milk secretion during regular forestripping detected by farm personnel) observed within the first 30 DIM (4.0\%) did not allow for its evaluation as an outcome in the present study.

In agreement with previous research in Holstein cows, we did not observe an effect of oral calcium supplementation on risk of pregnancy at first service or hazard of pregnancy by 150 DIM (Oetzel and Miller, 2012; Leno et al., 2018). Nevertheless, Martinez et al. (2016b) observed increased proportion of multiparous cows pregnant at first service and pregnancy rate up to 210 DIM, following the administration of a higher oral calcium dose during the first $2 \mathrm{~d}$ postpartum $(86 \mathrm{~g} / \mathrm{d}$ ) and for a longer period of time (up to 4 DIM).

Peripartum oral calcium supplementation aims to help with postpartum calcium balance and mitigate hypocalcemia effects on health, production, and reproduction. Thus, it would be expected that serum calcium concentration before oral calcium supplementation would have implications on its effects. However, although blood calcium dynamics varied based on calcemic status before oral calcium supplementation in the former 
study by our group (Valldecabres et al., 2018), serum calcium concentration before treatment administration did not interfere with treatment response for any of the evaluated outcomes in the present study. In contrast, Leno et al. (2018) reported a tendency for higher milk yield across the first 4 monthly tests in multiparous Holstein cows with serum calcium concentration $\leq 2.15$ $\mathrm{mmol} / \mathrm{L}$ before supplementation with a single dose of oral calcium in the day of calving. The same study also reported an increased first service pregnancy risk for supplemented cows with serum calcium concentration $>2.10 \mathrm{mmol} / \mathrm{L}$ before supplementation, and a tendency for decreased hazard of pregnancy by 150 DIM for supplemented cows with serum calcium concentration $\leq 1.95 \mathrm{mmol} / \mathrm{L}$ before supplementation. The sample size available to assess the treatment by serum calcium concentration effect, as well as the degree of hypocalcemia in the study herds may have limited the power of the present study to detect the effects of serum calcium concentration before supplementation on treatment response. Recent research suggests that the time relative to parturition when blood calcium concentration is assessed plays a role on its association with productive and health outcomes (Neves et al., 2018); thus, it is plausible that the serum calcium concentration assessed within the first $5 \mathrm{~h}$ following parturition may not have the strongest association with the evaluated productive and reproductive outcomes. In addition, the improved calcemia following oral calcium supplementation observed in the former study by our group was only evident up to 2 DIM (Valldecabres et al., 2018); the limited size or absence of effects observed for the evaluated productive and reproductive outcomes may also indicate that calcemia within the first $48 \mathrm{~h}$ following parturition may not be strongly associated with the evaluated outcomes. For instance, Neves et al. (2018) and McArt and Neves (2020) observed that it was not until 3 DIM that lower plasma calcium concentration was associated with lower milk yield and that hypocalcemia limited to the day of calving was instead associated with higher milk yield. Thus, while oral calcium supplementation strategies limited to the day of calving may have positive effects on health outcomes (Leno et al., 2018), if the strategy aims to improve productive and reproductive outcomes, strategies that provide calcium at higher doses for extended periods of time or later after parturition may be more appropriate and need to be further researched (Martinez et al., 2016b; Neves et al., 2018; McArt and Neves, 2020).

\section{CONCLUSIONS}

Oral supplementation with 50 to $60 \mathrm{~g}$ of calcium at 0 and 1 DIM to multiparous Jersey and Jersey $\times$ Hol- stein crossbreed cows had minimal effects at the group level but increased milk yield and ECM yield across the first 3 monthly tests for supplemented cows with a previous lactation length within the fourth quartile. Oral calcium supplementation also tended to increase peak milk yield for cows with a calving locomotion score $\geq 2$, and to decrease ECM yield across the first 3 monthly tests for cows with previous lactation length within the first quartile. Oral calcium supplementation did not affect milk fat concentration, protein concentration, and SCC linear score across the first 3 monthly tests, risk of pregnancy at first service, and hazard of pregnancy by 150 DIM. Serum calcium concentration before treatment administration did not influence the response to oral calcium supplementation. Further studies should evaluate different strategies of oral calcium supplementation and the identified subpopulations to evaluate the profitability of postpartum blanket oral calcium supplementation in multiparous Jersey and Jersey $x$ Holstein crossbreed cows from commercial dairy farms.

\section{ACKNOWLEDGMENTS}

Financial support for this research was provided by Bio-Vet Inc. (Barneveld, WI). The authors appreciate the collaboration of the 2 enrolled commercial dairy farms in California in allowing us to use their facilities, cows, and records. We gratefully acknowledge the support from Diego Rolle, Sonia Rodríguez, Sebastian Castaño, Victor José Ramírez (VMTRC, Tulare, CA), and Cedric Blanc (Lely North America, Pella, IA) during sample collection. Special appreciation is extended to Bill Verboort from AgriTech Analytics (Visalia, CA) for providing additional information used in the present study. This study was funded by Bio-Vet Inc.; the authors have not stated any other conflicts of interest.

\section{REFERENCES}

Amanlou, H., A. P. Akbari, N. E. Farsuni, and N. Silva-del-Río. 2016. Effects of subcutaneous calcium administration at calving on mineral status, health, and production of Holstein cows. J. Dairy Sci. 99:9199-9210. https://doi.org/10.3168/jds.2015-10844.

Caixeta, L. S., P. A. Ospina, M. B. Capel, and D. V. Nydam. 2017. Association between subclinical hypocalcemia in the first 3 days of lactation and reproductive performance of dairy cows. Theriogenology 94:1-7. https://doi.org/10.1016/j.theriogenology.2017.01 .039 .

Chapinal, N., S. J. LeBlanc, M. E. Carson, K. E. Leslie, S. Godden, M. Capel, J. E. P. Santos, M. W. Overton, and T. F. Duffield. 2012. Herd-level association of serum metabolites in the transition period with disease, milk production, and early lactation reproductive performance. J. Dairy Sci. 95:5676-5682. https://doi.org/10 .3168/jds.2011-5132.

Dohoo, I., W. Martin, and H. Stryhn. 2012. Methods in Epidemiologic Research. 1st ed. VER Inc., Charlottetown, Prince Edward Island, Canada.

Ferguson, J. D., D. T. Galligan, and N. Thomsen. 1994. Principal descriptors of body condition score in Holstein cows. J. Dairy Sci. 
77:2695-2703. https://doi.org/10.3168/jds.S0022-0302(94)77212 $-\mathrm{X}$.

Goff, J. P. 2008. The monitoring, prevention, and treatment of milk fever and subclinical hypocalcemia in dairy cows. Vet. J. 176:50-57. https://doi.org/10.1016/j.tvjl.2007.12.020.

Goff, J. P. 2018. Invited review: Mineral absorption mechanisms, mineral interactions that affect acid-base and antioxidant status, and diet considerations to improve mineral status. J. Dairy Sci. 101:2763-2813. https://doi.org/10.3168/jds.2017-13112.

Goff, J. P., A. Liesegang, and R. L. Horst. 2014. Diet-induced pseudohypoparathyroidism: A hypocalcemia and milk fever risk factor. J. Dairy Sci. 97:1520-1528. https://doi.org/10.3168/jds.2013-7467.

Goff, J. P., T. A. Reinhardt, and R. L. Horst. 1995. Milk fever and dietary cation-anion balance effects on concentration of vitamin D receptor in tissue of periparturient dairy cows. J. Dairy Sci. 78:2388-2394. https://doi.org/10.3168/jds.S0022-0302(95)76867 $-9$.

Jawor, P. E., J. M. Huzzey, S. J. LeBlanc, and M. A. G. von Keyserlingk. 2012. Associations of subclinical hypocalcemia at calving with milk yield, and feeding, drinking, and standing behaviors around parturition in Holstein cows. J. Dairy Sci. 95:1240-1248. https://doi.org/10.3168/jds.2011-4586.

Lean, I. J., P. J. DeGaris, D. M. McNeil, and E. Block. 2006. Hypocalcemia in dairy cows: Meta-analysis and dietary cation anion difference theory revisited. J. Dairy Sci. 89:669-684. https://doi .org/10.3168/jds.S0022-0302(06)72130-0.

Leno, B. M., R. C. Neves, I. M. Louge, M. D. Curler, M. J. Thomas, T. R. Overton, and J. A. A. McArt. 2018. Differential effects of a single dose of oral calcium based on postpartum plasma calcium concentration in Holstein cows. J. Dairy Sci. 101:3285-3302. https: //doi.org/10.3168/jds.2017-13164.

Martinez, N., L. D. P. Sinedino, R. S. Bisinotto, R. Daetz, C. Lopera, C. A. Risco, K. N. Galvão, W. W. Thatcher, and J. E. P. Santos. 2016a. Effects of oral calcium supplementation on mineral and acid-base status, energy metabolites, and health of postpartum dairy cows. J. Dairy Sci. 99:8397-8416. https://doi.org/10.3168/ jds.2015-10527.

Martinez, N., L. D. P. Sinedino, R. S. Bisinotto, R. Daetz, C. A. Risco, K. N. Galvão, W. W. Thatcher, and J. E. P. Santos. 2016b. Effects of oral calcium supplementation on productive and reproductive performance in Holstein cows. J. Dairy Sci. 99:8417-8430. https:/ /doi.org/10.3168/jds.2015-10529.

McArt, J. A. A., and R. C. Neves. 2020. Association of transient, persistent, or delayed subclinical hypocalcemia with early lactation disease, removal, and milk yield in Holstein cows. J. Dairy Sci. 103:690-701. https://doi.org/10.3168/jds.2019-17191.

Melton, L. A., M. L. Tracy, and G. Möller. 1990. Screening trace elements and electrolytes in serum by inductively-coupled plasma emission spectrometry. Clin. Chem. 36:247-250. https://doi.org/ 10.1093/clinchem/36.2.247.

Neves, R. C., B. M. Leno, K. D. Bach, and J. A. A. McArt. 2018. Epidemiology of subclinical hypocalcemia in early-lactation Holstein dairy cows: The temporal associations of plasma calcium concentration in the first 4 days in milk with disease and milk production. J. Dairy Sci. 101:9321-9331. https://doi.org/10.3168/ jds.2018-14587.

Neves, R. C., B. M. Leno, T. Stokol, T. R. Overton, and J. A. A. McArt. 2017. Risk factors associated with postpartum subclinical hypocalcemia in dairy cows. J. Dairy Sci. 100:3796-3804. https:// doi.org/10.3168/jds.2016-11970.

Oetzel, G. R. 2013. Oral calcium supplementation in peripartum dairy cows. Vet. Clin. North Am. Food Anim. Pract. 29:447-455. https: //doi.org/10.1016/j.cvfa.2013.03.006.

Oetzel, G. R., and B. E. Miller. 2012. Effect of oral calcium bolus supplementation on early-lactation health and milk yield in commercial dairy herds. J. Dairy Sci. 95:7051-7065. https://doi.org/ 10.3168/jds.2012-5510.

Ospina, P. A., D. V. Nydam, and T. J. DiCiccio. 2012. Technical note: The risk ratio, an alternative to the odds ratio for estimating the association between multiple risk factors and a dichotomous outcome. J. Dairy Sci. 95:2576-2584. https://doi.org/10.3168/jds .2011-4515.

Østergaard, S., and T. Larsen. 2000. Short communication: Associations between blood calcium status at calving and milk yield in dairy cows. J. Dairy Sci. 83:2438-2440. https://doi.org/10.3168/ jds.S0022-0302(00)75134-4.

Pedersen, K. O. 1972. Binding of calcium to serum albumin II. Effect of $\mathrm{pH}$ via competitive hydrogen and calcium ion binding to the imidazole groups of albumin. Scand. J. Clin. Lab. Invest. 29:75-83. https://doi.org/10.3109/00365517209081058.

Reinhardt, T. A., J. D. Lippolis, B. J. McCluskey, J. P. Goff, and R. L. Horst. 2011. Prevalence of subclinical hypocalcemia in dairy herds. Vet. J. 188:122-124. https://doi.org/10.1016/j.tvjl.2010.03.025.

Ribeiro, E. S., F. S. Lima, L. F. Greco, R. S. Bisinotto, A. P. A. Monteiro, M. Favoreto, H. Ayres, R. S. Marsola, N. Martinez, W. W. Thatcher, and J. E. P. Santos. 2013. Prevalence of periparturient diseases and effects on fertility of seasonally calving grazing dairy cows supplemented with concentrates. J. Dairy Sci. 96:5682-5697. https://doi.org/10.3168/jds.2012-6335.

Roche, J. R., and D. P. Berry. 2006. Periparturient climatic, animal, and management factors influencing the incidence of milk fever in grazing systems. J. Dairy Sci. 89:2775-2783. https://doi.org/10 .3168/jds.S0022-0302(06)72354-2.

Rodríguez, E. M., A. Arís, and A. Bach. 2017. Associations between subclinical hypocalcemia and postparturient diseases in dairy cows. J. Dairy Sci. 100:7427-7434. https://doi.org/10.3168/jds .2016-12210.

Rodríguez, E. M., A. Bach, M. Devant, and A. Aris. 2016. Is calcitonin an active hormone in the onset and prevention of hypocalcemia in dairy cattle? J. Dairy Sci. 99:3023-3030. https://doi.org/10.3168/ jds.2015-10229.

Siverson, A., C. F. Vargas-Rodriguez, and B. J. Bradford. 2014. Short communication: Effects of molasses products on productivity and milk fatty acid profile of cows fed diets high in dried distillers grains with solubles. J. Dairy Sci. 97:3860-3865. https://doi.org/ 10.3168/jds.2014-7902.

Sprecher, D. J., D. E. Hostetler, and J. B. Kaneene. 1997. A lameness scoring system that uses posture and gait to predict dairy cattle reproductive performance. Theriogenology 47:1179-1187. https:// doi.org/10.1016/S0093-691X(97)00098-8.

USDA-NAHMS. 2014a. National Animal Health Monitoring System (NAHMS). 2014. Health and Management Practices on U.S. Dairy Operations. USDA NAHMS, Fort Collins, CO.

USDA-NAHMS. 2014b. National Animal Health Monitoring System (NAHMS). 2014. Dairy cattle management practices in the United States. USDA NAHMS, Fort Collins, CO.

Valldecabres, A., J. A. A. Pires, and N. Silva-del-Río. 2018. Effect of prophylactic oral calcium supplementation on postpartum mineral status and markers of energy balance of multiparous Jersey cows. J. Dairy Sci. 101:4460-4472. https://doi.org/10.3168/jds.2017 $-12917$.

Valldecabres, A., J. A. A. Pires, and N. Silva-del-Río. 2019. Cow-level factors associated with subclinical hypocalcemia at calving in multiparous Jersey cows. J. Dairy Sci. 102:8367-8375. https://doi.org/ $10.3168 /$ jds.2018-16180.

Vergara, C. F., D. Döpfer, N. B. Cook, K. V. Nordlund, J. A. A. McArt, D. V. Nydam, and G. R. Oetzel. 2014. Risk factors for postpartum problems in dairy cows: Explanatory and predictive modeling. J. Dairy Sci. 97:4127-4140. https://doi.org/10.3168/jds .2012-6440.

\section{ORCIDS}

Ainhoa Valldecabres @ 1 https://orcid.org/0000-0002-3235-2487 Noelia Silva-del-Río @ https://orcid.org/0000-0002-2826-6797 